\title{
Com qui troba un poema: una proposta didàctica per a l'aula de català com a llengua estrangera
}

\author{
Cristina Fernández Recasens \\ Universitat de Birmingham \\ cfern49@xtec.cat
}

Rebut: 28 de març del 2020

Acceptat: 1 de juliol del 2020

\section{Resum}

Poemes amb bigoti proposa fer explícita la lectura pròpia que cada lector fa d'un poema mitjançant una activitat que permet l'apropiació del text poètic. Es tracta d'una proposta didàctica dissenyada per acostar la poesia als alumnes, posant èmfasi en la idea de dessacralització d'aquest gènere.

\section{Paraules clau}

intermedialitat, creativitat, escriptura, poesia, expressió oral, expressió escrita

\section{Justificació i objectius}

Dins l'àmbit de la didàctica de la poesia, diversos estudis recullen les limitacions amb què es troba el professorat a l'hora de treballar amb aquest gènere a l'aula, i alguns dels principals factors que destaquen són la reculada generalitzada de la literatura enfront una major presència de la llengua, els prejudicis del professorat i l'alumnat, la limitació dels materials didàctics o l'estretor del cànon (Ferrer, 2009; Arenas i Madrenas, 2010; Fernández i Masgrau, 2016; Picornell, 2018). Això ocorre a diversos nivells educatius: a primària, a secundària i també a l'àmbit universitari. Malauradament, la relació de la majoria d'estudiants amb la poesia sol acabar el dia en què es graduen, tot i que a l'aula s'hi dediquen força temps i recursos:

Poetry dies for most people on graduation day. The thickest coat of dust in a public library can be found in its poetry section. Considering how much time is spent in secondary classrooms dissecting poetry, one would expect graduates to be ravenous poetry consumers. Wrong. Why is this so? (Trelease, 2013, 22).

La poesia és sovint considerada un gènere difícil de tractar a classe o no apte per a tots els públics. A vegades és imposada pel calendari i la rebem com a recurs que ve donat per la celebració de Nadal, del Dia Mundial de la Poesia o de la Diada Sant Jordi. 


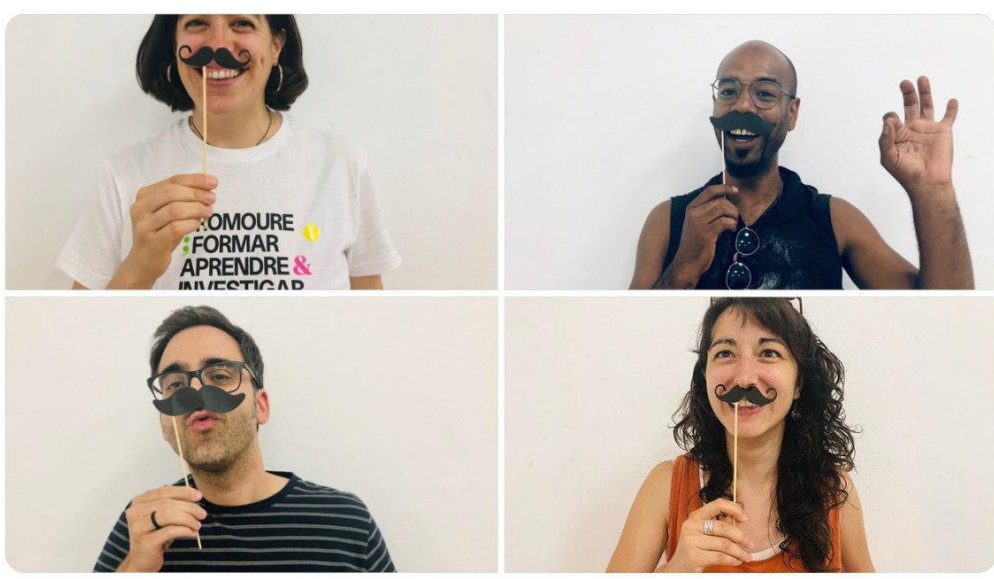

Fig 1. Participants al Taller de poemes amb bigoti, JIPC, Palma (2019)

En el cas concret de la didàctica de la llengua catalana com a llengua estrangera, potser els poemes no són els primers textos que ens venen al cap per treballar a classe, ja que pensem que l'alumnat s'hi mostrarà més reticent o que els textos poètics li seran menys accessibles, especialment als nivells inicials i intermedis. I també, segurament, si decidim treballar la poesia tendim a proposar als nostres estudiants activitats de comprensió i d'interpretació, o de traducció dels textos més que no pas activitats que promoguin la creació poètica.

Tenint en compte els postulats de l'educació alliberadora (Freire, 1970), cal facilitar l'accés i el gaudi de la poesia als nostres estudiants per evitar que es mantingui dins les elits socials i culturals (Rodari, 2009). A més, tal com recorda Georges Jean (1996), tot acte poètic és un acte creador i, per tant, tot lector és creador i recreador d'allò que llegeix. En aquest sentit, Poemes amb bigoti proposa fer explícita la lectura pròpia que cada lector fa d'un poema mitjançant una activitat que permet l'apropiació del text poètic. Es tracta d'una proposta didàctica dissenyada per acostar la poesia a l'alumnat, posant èmfasi en la idea de dessacralització. Es pretén contribuir al trencament dels prejudicis que desperta el gènere entre el professorat i l'alumnat, i potenciar la creació escrita des d'una vessant lúdica.

\section{Descripció}

El taller comença amb l'observació de la Mona Lisa de Leonardo da Vinci (ca. 1502). Es projecta una imatge de l'obra a la pantalla i es demana als estudiants què en saben i si en coneixen l'autor. A continuació, es projecta una imatge de L.H.O.O.Q. de Marcel Duchamp (1919) i se'ls pregunta: "Per què Duchamp va dibuixar un bigoti a la Mona Lisa?" Llavors, s'anoten totes les idees que aporten els estudiants i, tot seguit, es planteja si és possible traslladar el que va fer Duchamp a la poesia; és a dir, si és possible «posar un bigoti» a un poema. A partir d'aquí, es fa una pluja d'idees amb els estudiants de les estratègies que se'ls acudeixen: retallar un poema, canviar-ne el sentit, barrejar diversos poemes, suprimir paraules, etc. En acabat, se'ls proporciona una sèrie de poemes impresos en paper i se'ls convida a modificar-los tot utilitzant materials diversos (retoladors, gomets, papers de diversos colors, revistes per fer collages, tisores, lletres adhesives, etc.).

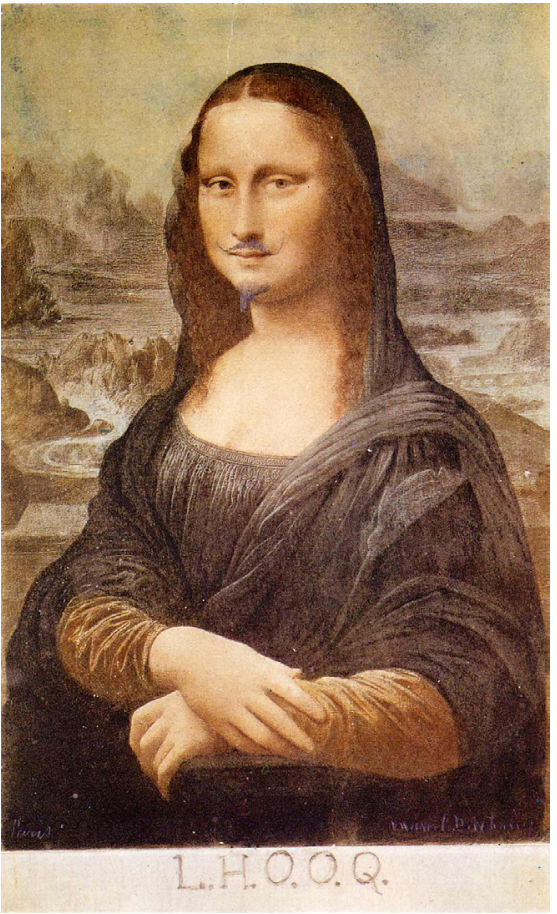

Fig 2. L.H.O.O.Q. Marcel Duchamp (1919) 
Quan han enllestit les seves creacions, cada participant presenta el seu poema amb bigoti al grup i, un cop finalitzat el taller, els poemes s'exposen durant uns dies.

Es tracta, doncs, d'aplicar a l'escriptura poètica la tècnica de l'objet trouvé o ready-made. De la mateixa manera que Duchamp pren una postal de la Mona Lisa i la transforma en una obra d'art, ens podem apropiar d'un poema i modificar-lo per proposar-ne una lectura alternativa i també com a punt de partida d'una creació pròpia. A més, la condició intrínsecament intermedial dels ready-mades facilita que els poemes amb bigoti que creen els participants incorporin una hibridació de llenguatges artístics:

Duchamp pieces are truly between media, between sculpture and something else, while a Picasso is readily classifiable as a painted ornament (...). The ready-made or found object, in a sense an intermedium since it was not intended to conform the pure medium, usually suggests this, and therefore suggests a location in the field between the general area of art media and those of life media (Higgins, 1965, 2).

Segons Pagès Jordà, el millor mètode d'aprenentatge de la literatura és la pràctica a través del joc: "Una vegada aprenem que la literatura és una art combinatòria, és fàcil establir que el millor mètode d'aprenentatge és la pràctica: s'aprèn a jugar (a escacs, a bàsquet, a escriure) a partir del joc, no de la memorització de regles" (Pagès, 2000). La proposta de poemes amb bigoti també incorpora aquest component lúdic i convida a incloure el joc a l'aula de llengua i literatura catalanes.

\section{Mostra de poemes amb bigoti dels estudiants de català de la Universitat de Birmingham}

A continuació, veurem una mostra de poemes amb bigoti elaborats pels estudiants de català de la Universitat de Birmingham. En els grups de nivell inicial i intermedi, a banda del poema en català, els estudiants disposaven d'una traducció del poema ${ }^{1}$.

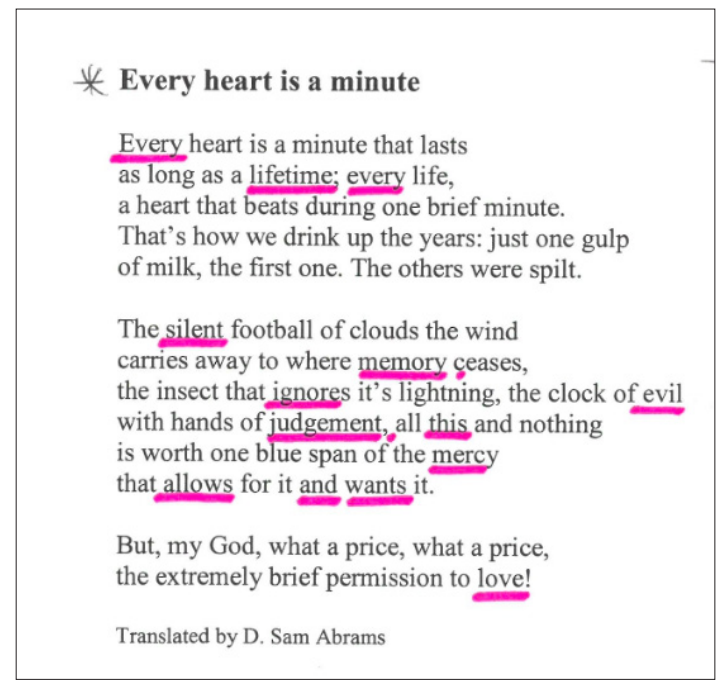

«Every lifetime, every silent memory ignores evil judgement, this mercy allows and wants love.»

1 Un recurs a tenir en compte per a les traduccions, per exemple, és la plataforma lyrikline.org, un repositori de poesia de la Literaturwerkstatt de Berlín on podem trobar traduccions de poesia contemporània en línia. 
So often in modern culture, the expectation is that you're a feminist, and you're angry. Angry at the world, angry at men, angry at Kleenex Mansize tissues. My approach with this poem, although far from groundbreaking, was a refreshing reminder of how I hope to approach any feminist conversations this International Women's Day: from a place of total love, compassion, and understanding.

\section{Nivell B1}

En aquest cas, es partia de la "Cansoneta leu e plana” de Maria Cabrera. L'alumna va retallar-ne tots els versos, els va reordenar i els va convertir en versos mòbils utilitzant massilla adhesiva per enganxar-los a la cartolina. També va afegir alguns versos propis: «soc que no soc una covarda», «soc que no soc una mala persona», "soc que no soc una bona persona». Quan el va presentar a classe, va ex-

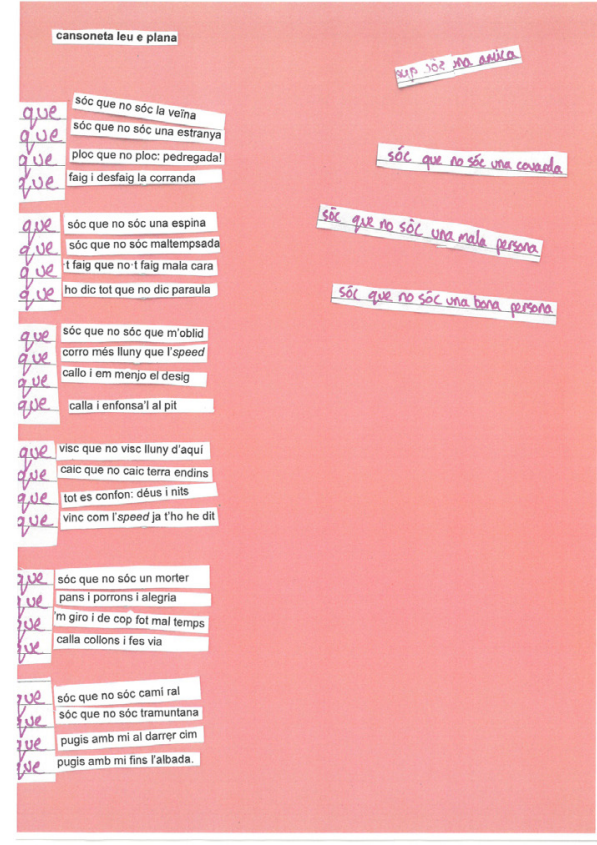

Fig 4. Mostra «Cansoneta leu e plana» plicar que volia fer un poema amb versos que es poguessin moure per expressar la idea que la identitat és fluïda i canvia al llarg de la vida.

En una altra mostra de la classe de nivell intermedi, es partia del poema "Saudade", d'Anna

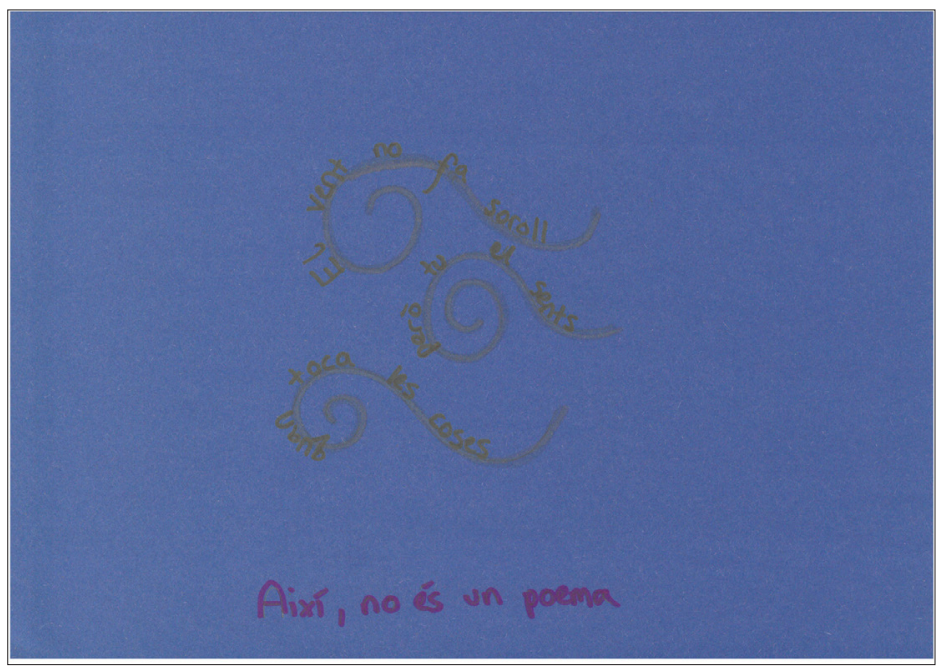

El vent no fa soroll però tu el sents quan toca les coses. Així, el poema.

Fig 5. Mostra «Així, no és un poema»

Gual:

L'alumna el va convertir en un cal-ligrama que representa les ondulacions del vent i li va canviar el títol pel d'“Així, no és un poema”, una referència a La traïció de les imatges, de Magritte, que apunta a la reflexió sobre els límits de la poesia: si al poema li canviem la forma, ja no és un poema?

\section{Nivell C1}

Aquí, el poema "L'espera", de Joana Raspall, esdevé un poema desplegable: el temps pot passar més ràpid o més lent segons de les emocions de cada moment. Els enamorats saben que "qui espera, desespera" i l'estudiant fa explícita aquesta lectura del text fent uns plecs al paper que permeten obrir i tancar el poema: per remarcar-ho, hi dibuixa un rellotge que, d'altra banda, recorda els rellotges tous dalinians. 


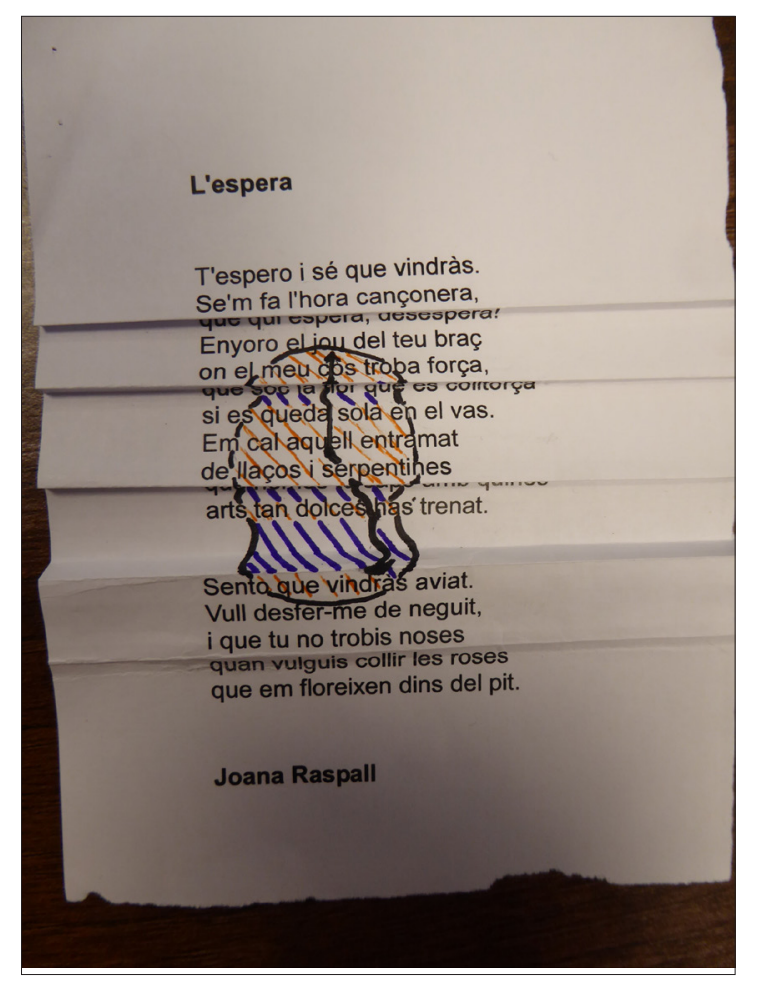

Fig 6. Mostra «L'espera»

\section{Conclusions}

Aquesta proposta didàctica vol ser una invitació a llegir poesia d'una manera desacomplexada. Llegir no és una activitat passiva, a tot el que llegim hi afegim alguna cosa que només és nostra. Com qui troba un poema: deixem que el text ens parli, però també nosaltres li diem coses. Els poemes amb bigoti són una manera de fotografiar aquesta mirada única de cada lector sobre un text, en un moment determinat. També, a l'aula de català com a llengua estrangera, poden ser una porta d'entrada a la literatura catalana i una oportunitat per a l'estudi de la llengua.

\section{Referències}

Arenas, C. i Madrenas, D. (2010). Per què poesia contemporània a l'aula? En: Bordons, G. (coord.), Poesia i educació: d'internet a l'aula (77-92). Graó.

Fernández, C. i Masgrau, J. (2016). Dancing Words: A Didactic Experience. En: Burnard, P. et al (2016). Building Interdisciplinarity and Intercultural Bridges, where practic meets research and theory. E-book of selected articles from BIBACC International Conference, 95-103. University of Cambridge. Recuperat de http://bibacc.org/ebook2016/

Ferrer, J. (2009). Punt de partida: les actituds envers el gènere poètic a la Facultat de Formació del Professorat de la Universitat de Barcelona. En: Bordons, G. (coord.) (2009). La poesia contemporània. Una eina per canviar actituds en els futurs mestres i per millorar la llengua (11-19). Graó.

Freire, P. (1970). Pedagogía del oprimido. Tierra Nueva.

Higgins, D. (1965). Synesthesia and intersenses: intermedia. Something Else Newsletter 1, Núm 1.

Jean, G. (1996). La poesía en la escuela. Hacia una escuela de la poesía. Ediciones de la Torre.

Picornell, M. (2018). Hàbits de consum cultural dels estudiants del grau de llengua i literatura catalanes a la Universitat de les Illes Balears. Presentació del projecte i resultats inicials. UTE. 
Revista de Ciències de l'Educació, 1, 60-79. Recuperat de revistes.publicacionsurv.cat/index. php/ute

Pagès, V. (2000). Un taller literari a primer cicle d'ESO. Articles de Didàctica de La Llengua i de La Literatura, 89-98.

Rodari, G. (2009) Gramàtica de la fantasia. Introducció a l'art d'inventar històries. Educaula.

Trelease, J. (2013). The Read-Aloud Handbook. En: Laski, D. et al (ed). (2013). Open the door. How to excite young people about poetry. The Poetry Foundation and McSweeney's Publishing. 